\title{
Atmospheric carbonyl sulfide (OCS) measured remotely by FTIR solar absorption spectrometry
}

Geoffrey C. Toon et al.

Correspondence to: Geoffrey C. Toon (geoffrey.c.toon@jpl.nasa.gov)

The copyright of individual parts of the supplement might differ from the CC BY 3.0 License. 
Figure SI.1. The following 6 pages show spectral fits to MkIV balloon spectra measured above Ft. Sumner, New Mexico in September 1993. The black diamond symbols represent the measured transmittances, and the black line is the fitted calculation. The colored lines are the contributions of the various fitted gases to the fitted calculation. The narrow panel at the top of each spectral fit shows the spectral fitting residuals (measured-calculated). This figure shows the same data as Fig.1 of the main paper, but includes the contributions of the various interfering gases with an expanded $x$-scale, allowing them to be more clearly distinguished. As in Fig.1, the upper panels show fits to the $24.0 \mathrm{~km}$ tangent altitude spectrum, and the lower panels shows fits to the $8.6 \mathrm{~km}$ tangent altitude spectrum. The first four pages show consecutive sections of the 2038.1-2062.3 $\mathrm{cm}^{-1}$ window, each about $6 \mathrm{~cm}^{-1}$ wide. The last two pages show fits to the $2063.3-2076.0 \mathrm{~cm}^{-1}$ window. 

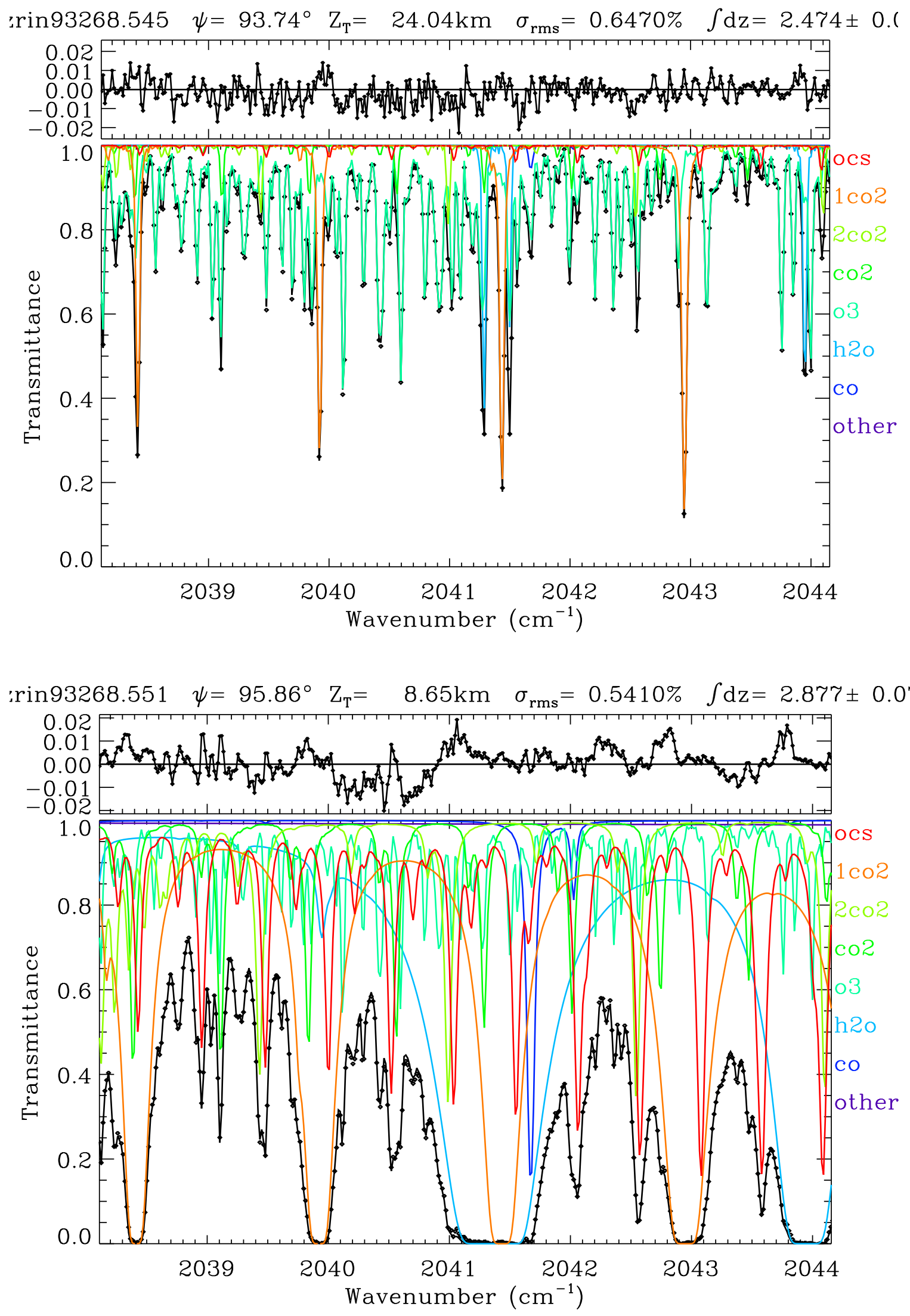

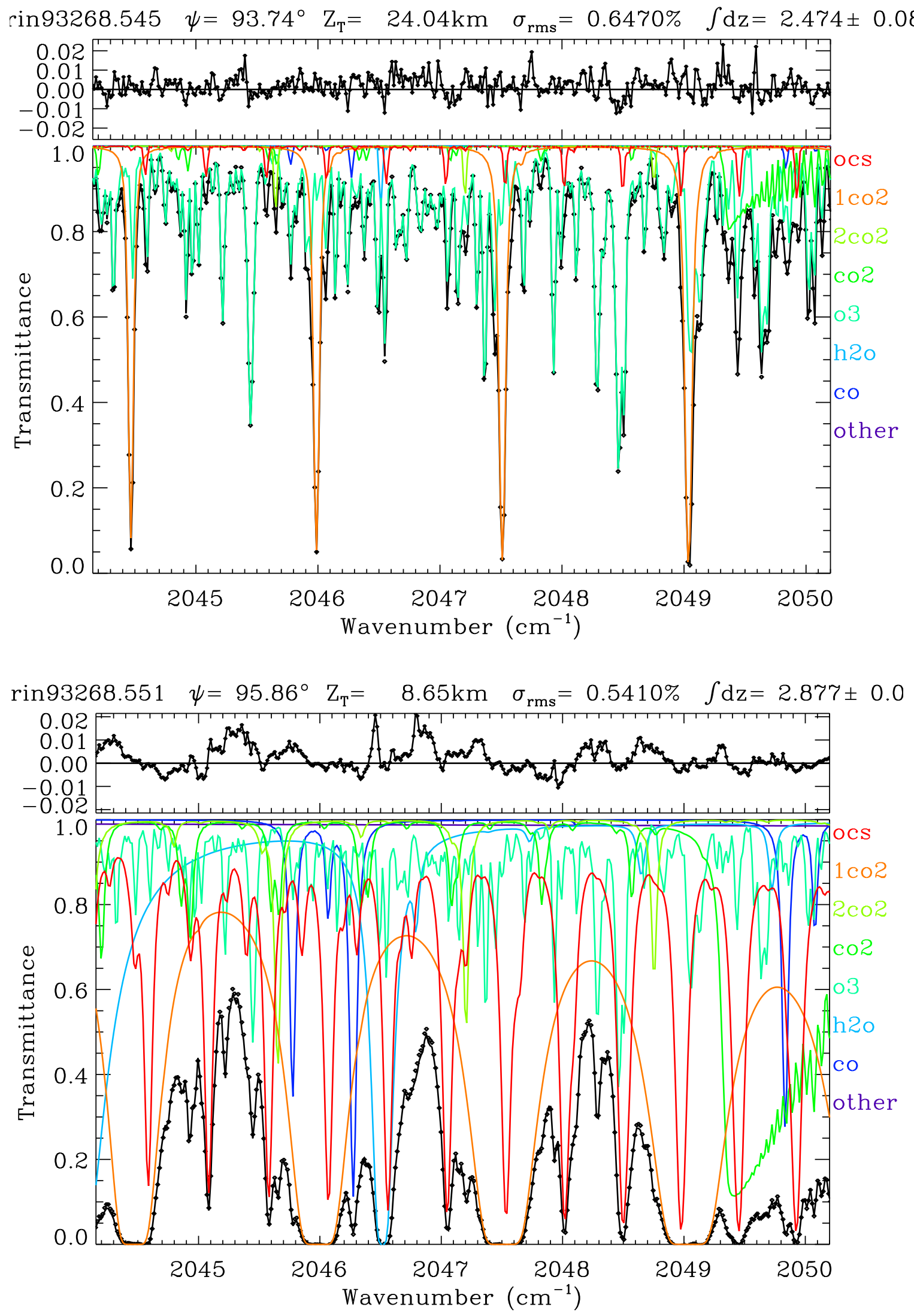

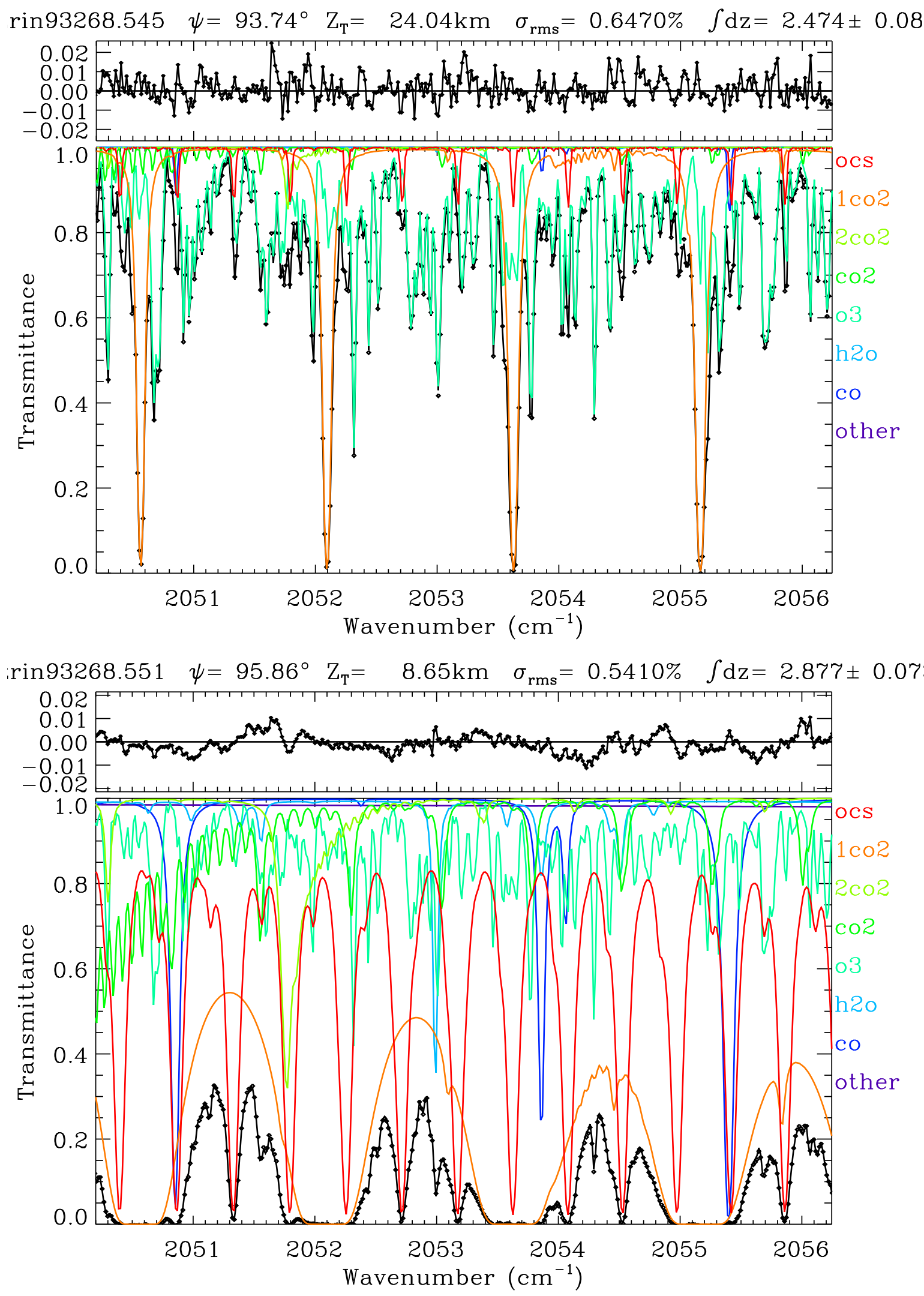

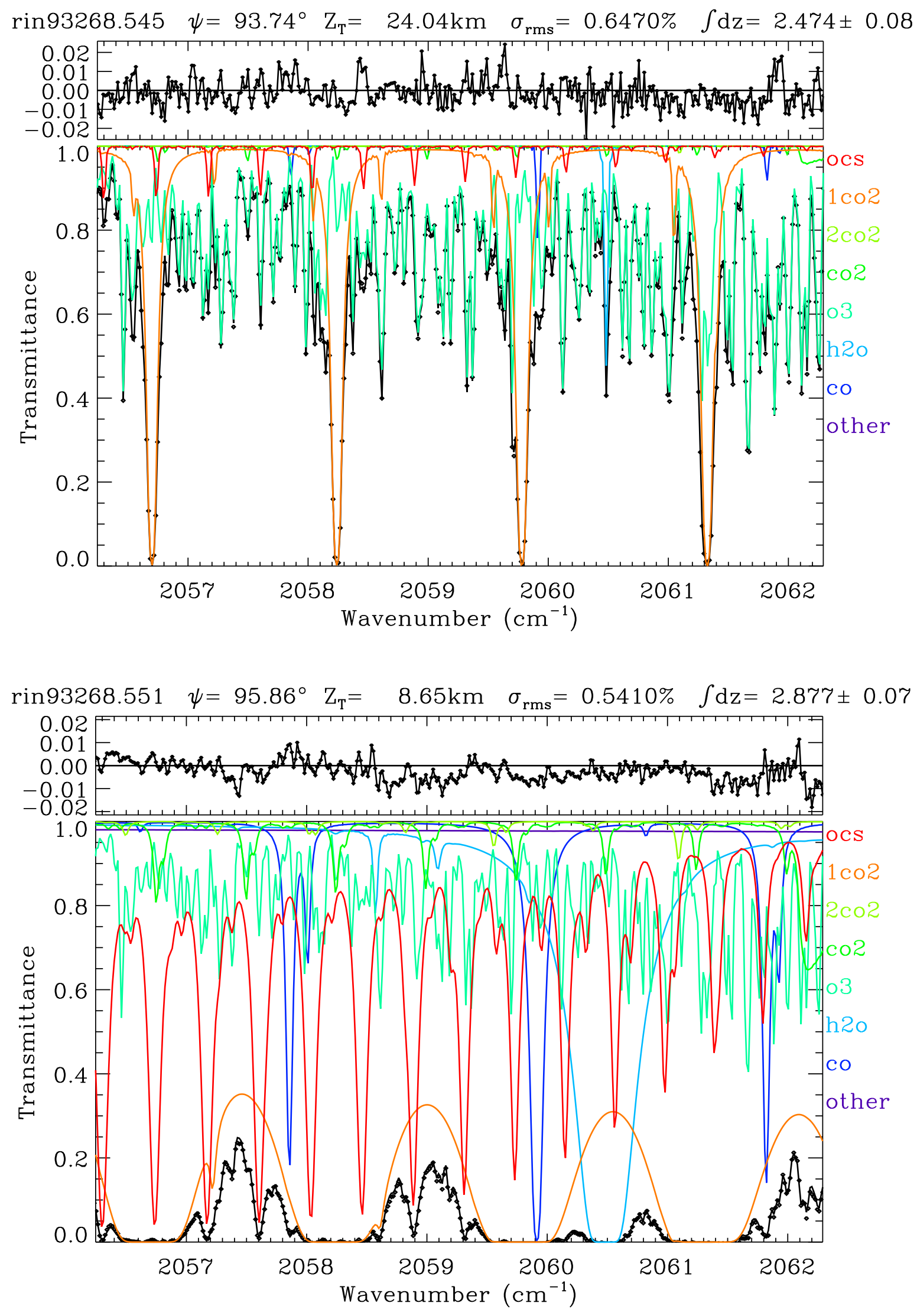

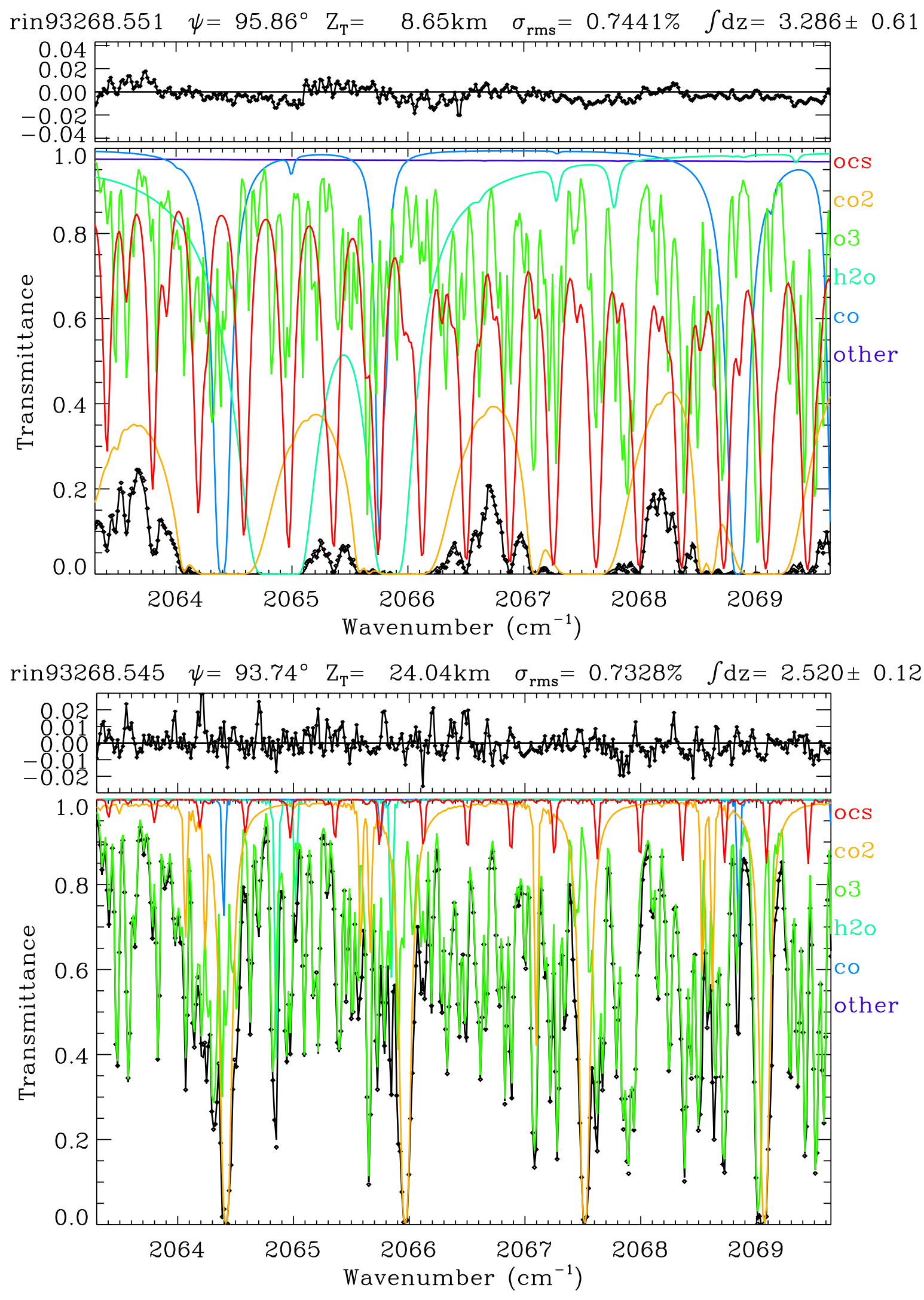

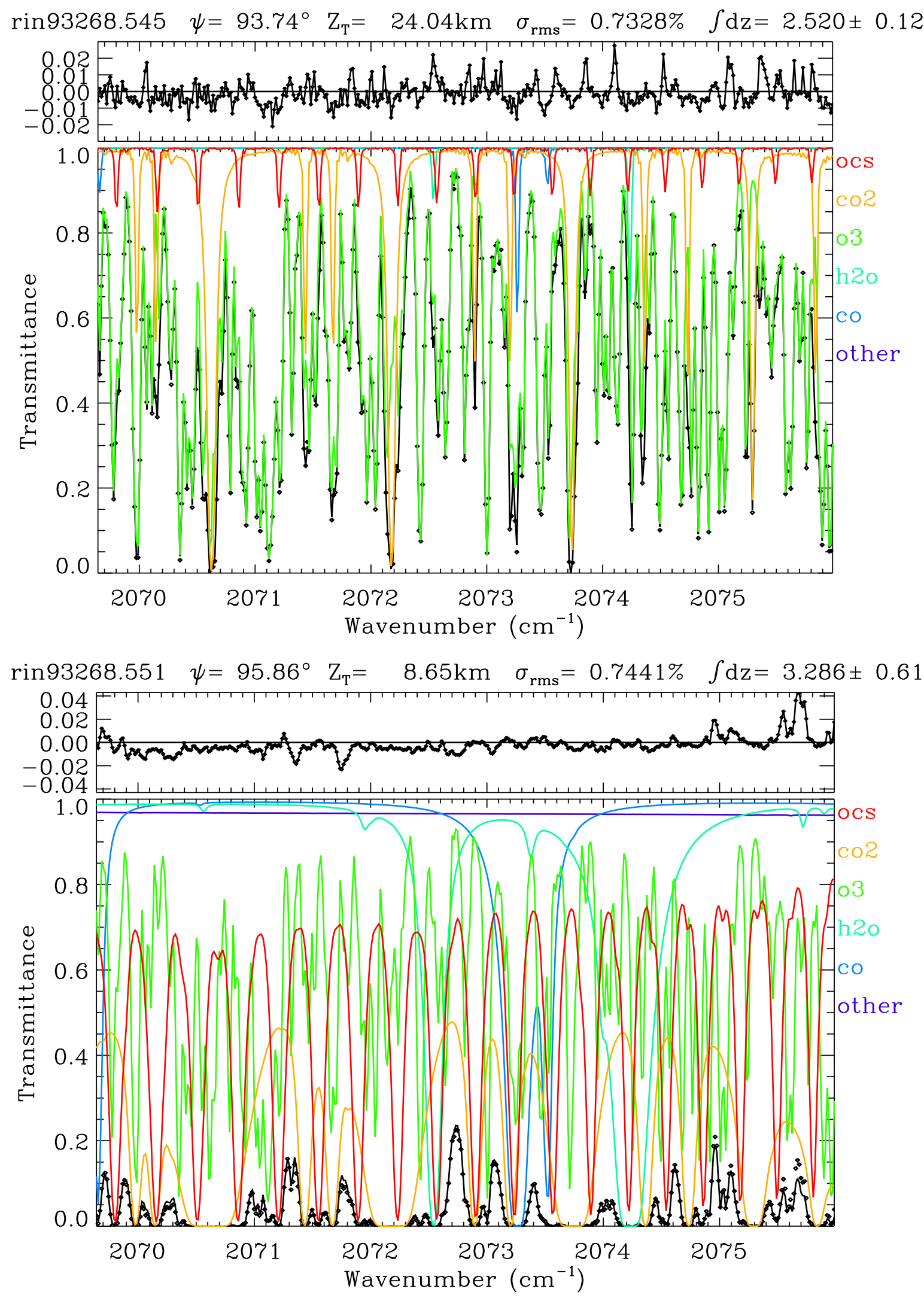